\title{
Relationship between Personality Traits and Course Subjective Well-Being: Mediating Effect of Self-Efficacy
}

\author{
Dong Yang1*, Xiaohui Yang², Hanhui Chen'1, Deliang Sun'1 \\ ${ }^{1}$ School of Business Administration, Anhui University of Finance and Economics, Bengbu, China \\ ${ }^{2}$ No. 2 Affiliated Hospital of Bengbu Medical College, Bengbu, China \\ Email: *yangdong@aufe.edu.cn
}

How to cite this paper: Yang, D., Yang, X.H., Chen, H.H. and Sun, D.L. (2020) Relationship between Personality Traits and Course Subjective Well-Being: Mediating Effect of Self-Efficacy. Open Access Library Journal, 7: e6010.

https://doi.org/10.4236/oalib.1106010

Received: December 19, 2019

Accepted: May 8, 2020

Published: May 11, 2020

Copyright $\odot 2020$ by author(s) and Open Access Library Inc.

This work is licensed under the Creative Commons Attribution International License (CC BY 4.0).

http://creativecommons.org/licenses/by/4.0/

\begin{abstract}
More and more courses are no longer based on the examination results to evaluate the effect. As the main participants, students are paid more attention to, especially their mental feelings. This paper explores the mediating effect of self-efficacy and the mutual relationship between personality traits and course subjective well-being. A questionnaire was conducted among 310 students in the course "comprehensive experiment of management", correlation and regression methods were used to investigate the relationship between variables. The course participation role, gender, family origin and subjective character identification all significantly affect the course subjective well-being. Openness has no significant correlation with course well-being, neuroticism has a negative correlation, and extroversion, agreeableness, conscientiousness and self-efficacy have a positive correlation. Self-efficacy has a complete mediating effect between neuroticism and course well-being and a partial mediating effect between extraversion, agreeableness, conscientiousness and course wellbeing. The course subjective well-being of students is influenced not only by their innate personality traits but also by their acquired self-efficacy.
\end{abstract}

\section{Subject Areas \\ Education, Sociology}

Keywords

Personality Traits, Course Subjective Well-Being, Self-Efficacy

\section{Literature Review}

Subjective Well-Being refers to the holistic assessment of the evaluator's life 
quality according to self-determined criteria [1]. With the economic and social development in China, the subjective well-being of different groups has become an important indicator to judge their psychological quality of life, students [2] [3], the elderly [4], left-behind children [5] and other groups have been used to study by scholars.

Subjective well-being (SWB), as individual psychological perception, is affected by individual personality traits certainly. In recent years, scholars have verified that personality traits are a powerful factor affecting SWB. Z.-Q. Li et al. [6] and Diener et al. [7] found that temperament personality traits (neuroticism and extroversion) play the strongest role in relationship with SWB. Furthermore, the research on the intermediary factors between has also become the focus of scholars' attention. Job involvement [8], Confucian psychological assets [9], self-efficacy [10] have been used as intermediary variables to study the relationship between personality and SWB.

Under the stimulation of objective reality and subjective evaluation, congenital personality traits will play a more important role [10]. That is, personality traits impact SWB by psychological cognition. The main life activities of college students are on the campus and in the classroom, the perception in the classroom will produce subjective psychological evaluation, and the accumulated learning experience will change the students' learning confidence. Self-efficacy is the result of individual cognition and evaluation of their ability. It mainly determines the personal action direction from perceptual cognition to final behavior [11], which can reflect the degree of individual affected by the accumulation of objective conditions. Therefore, this paper chooses self-efficacy as the intermediary variable.

This research chooses the students in a comprehensive training course as the sample. The course is in the way of competition among enterprises in a simulated business social environment. The course conducts in a continuous and centralized way, during which students experience a high intensity of psychological stress. Under this condition, the test can reflect the students' psychological perception in the course. Based on the above, this paper puts forward the concept of course subjective well-being; that is, the subjective well-being of the students in the course cycle.

To sum up, this research attempts to study the relationship between personality traits, self-efficacy, and subjective well-being in the course cycle.

\section{Sample and Methodology}

\subsection{Sample}

To determine the needed sample size (n), we use the formula below which is most popularly used in similar researches. After calculation, the minimum sample size is 299 .

$$
n=\frac{Z_{\alpha / 2}^{2} p(1-p) N}{\delta^{2}(N-1)+Z_{\alpha / 2}^{2} p(1-p)}
$$


where $\alpha$ represents the significance level, $\delta$ represents the allowable error, $p$ represents the general estimate population rate, and $\mathrm{N}$ represents the total samples.

This research selects 310 subjects from the course of Management Comprehensive Training in Anhui University of Finance and Economics (China), including 87 male students and 223 female students.

\subsection{Methodology}

\subsubsection{NEO-FFI Scale}

This research selects the NEO-FFI scale (NEO Five Factors Inventory, Big five Personality brief edition), including 60 items. Five personality traits (Neuroticism, Extraversion, Openness, Agreeableness, and Conscientiousness) can be obtained after the calculation. The scale has been widely used in psychology and personality traits research around the world [12] [13].

\subsubsection{General Self-Efficacy Scale}

This research selected the General Self-Efficacy Scale (GSES). It includes ten items and uses a five-point single-dimensional structure. The higher the total score indicates the stronger general self-efficacy. The internal consistency reliability of the scale in this study was 0.903 .

\subsubsection{Subjective Well-Being Scale}

The main indicators of SWB are satisfaction With Life Scale (SWLS) and Positive Affective and Negative Affective Scale (PANAS). According to the research of former scholars [14], the course satisfaction scale is designed for evaluating individual satisfaction in the course period. The questionnaire consists of 15 items, including students and curriculum two dimensions. After trial test-revisionformal test, the course satisfaction can be obtained. The internal consistency reliability of the scale is 0.951. PANAS is compiled by Watson et al., and its Chinese version is revised by Q.-A Li, L. Ai and Y. Zhang. The internal consistency reliability of positive emotion and negative emotion is 0.902 and 0.839 , respectively. After standardizing the scores, the scores of SWB were subtracted by course satisfaction plus positive emotions and minus negative emotions [15].

\subsection{Data Process}

SPSS22.0 was used for data processing, and this research also used correlation analysis, regression analysis, and Bootstrap mediating effects examine.

\section{Result and Analysis}

\subsection{Course Factors Affecting Subjective Well-Being}

This research has carried out ANOVA analysis about participants' background factors to their course SWB. The result can be seen in Table 1 .

This research classifies the participation role into four types: CEO, department management, financial staff, and others. In Table 1, the CEOs are significantly 
Table 1. Matrix of ANOVA result.

\begin{tabular}{|c|c|c|c|c|c|c|c|c|c|c|}
\hline \multicolumn{4}{|c|}{ Participation role } & \multicolumn{2}{|c|}{ Gender } & \multicolumn{3}{|c|}{ Source of family } & \multicolumn{2}{|c|}{ Self-evaluation } \\
\hline $\mathrm{CEO}$ & $\begin{array}{l}\text { Department } \\
\text { manager }\end{array}$ & Financial staff & others & male & female & urban & Town & rural & Independence & Dependence \\
\hline 84.21 & 79.96 & 79.13 & 77.39 & 76.89 & 80.45 & 80.09 & 82.79 & 77.49 & 80.89 & 76.90 \\
\hline \multicolumn{4}{|c|}{$\mathrm{p}=0.135$} & \multicolumn{2}{|c|}{$p=0.056$} & \multicolumn{3}{|c|}{$p=0.02$} & \multicolumn{2}{|c|}{$\mathrm{p}=0.02$} \\
\hline
\end{tabular}

Note: the table is calculated by SPSS22.0.

more course SWB than that of other roles.

The significance of the ANOVA analysis for gender to course well-being was 0.056. It indicates that gender had a significant impact on the course SWB. The course SWB of female students is higher than male students', and this is consistent with the results of L. Qiu et al. [16].

The family source of students also had a significant difference in course SWB $(p<0.05)$. The course SWB of students from rural areas was lower than those from urban and towns.

According to the theory of American psychological management scientist H.A. Witkin, the individual independent personality of the students was divided into two items. It includes independence (good at thinking and solving problems independently, without panic in emergencies, and even like to impose their ideas on others) and dependence (vulnerable to the influence by others, dependent on others and often hesitant). The results showed that there was a significant difference between the two subjective personality cognizance $(\mathrm{p}<0.05)$. The course SWB of the students who identified themselves as independent was higher than that of the dependent students.

\subsection{Correlation of Big Five Personality, Self-Efficacy and SWB}

After Pearson correlation analysis (see Table 2), among these variables in the course, there are 3 pair uncorrelated variables: openness and SWB, openness and neuroticism, openness and extraversion. While the other variables were significantly correlated respectively. Meanwhile, except neuroticism and SWB were negatively correlated, other personality traits, self-efficacy, and course SWB were significantly positively correlated.

\subsection{Test of the Mediating Effect of Self-Efficacy on Personality Trait and Course SWB}

Referring to the mediation effect test process proposed by Z.-L. Wen et al. [17] Taking the big five personality traits as the independent variable and course SWB as the dependent variable, the Bootstrap test was conducted on the mediating effect of self-efficacy. The results are shown in Tables 3-6.

Self-efficacy had a suppressing effect between openness and course SWB (openness and course SWB regression coefficient were not significant), while neuroticism, extroversion, agreeableness, conscientiousness, and course SWB 
Table 2. Correlation matrix of big five traits, self-efficacy and course SWB.

\begin{tabular}{|c|c|c|c|c|c|c|c|}
\hline & Neuroticism & Extraversion & Openness & Agreeableness & Conscientiousness & Self-efficacy & SWB \\
\hline Neuroticism & 1 & & & & & & \\
\hline Extraversion & $-0.52^{\star *}$ & 1 & & & & & \\
\hline Openness & -0.09 & 0.09 & 1 & & & & \\
\hline Agreeableness & $-0.41^{\star *}$ & $0.36^{* *}$ & 0.10 & 1 & & & \\
\hline Conscientiousness & $-0.58^{\star *}$ & $0.46^{* *}$ & $0.15^{\star *}$ & $0.49^{* *}$ & 1 & & \\
\hline Self-efficacy & $-0.39^{* *}$ & $0.37^{* *}$ & $0.14^{*}$ & $0.16^{* *}$ & $0.41^{\star *}$ & 1 & \\
\hline SWB & $-0.20^{\star *}$ & $0.41^{\star *}$ & -0.004 & $0.18^{\star *}$ & $0.24^{\star *}$ & $0.28^{\star *}$ & 1 \\
\hline
\end{tabular}

Note: ${ }^{\star}$ means $\mathrm{p}<0.05,{ }^{\star *}$ means $\mathrm{p}<0.01$.

Table 3. Mediating effect test of self-efficacy in neuroticism and course SWB.

\begin{tabular}{ccc}
\hline coefficient & Regression coefficient & Sig. \\
\hline c & -0.196 & 0.001 \\
a & -0.025 & 0.000 \\
b & 7.128 & 0.000 \\
c & -0.186 & 0.095 \\
\hline
\end{tabular}

Note: the figure in the table is calculated by SPSS22.0. $\mathrm{ab} / \mathrm{c}^{\prime}=95.2 \%$ (the ratio of indirect effect to direct effect), this indicates the direct effect is not significant; it only has the mediating effect between neuroticism and course SWB.

Table 4. Mediating effect test of self-efficacy in openness and course SWB.

\begin{tabular}{ccc}
\hline coefficient & Regression coefficient & Sig. \\
\hline c & 0.405 & 0.000 \\
a & 0.029 & 0.000 \\
b & 4.504 & 0.007 \\
c & 0.784 & 0.000 \\
\hline
\end{tabular}

Note: the figure in the table is calculated by SPSS22.0. $\mathrm{ab} / \mathrm{c}^{\prime}=16.5 \%$, this indicates the direct effect is significant; there may have other mediating variables between extraversion and course SWB.

Table 5. Mediating effect test of self-efficacy in agreeableness and course SWB.

\begin{tabular}{ccc}
\hline coefficient & Regression coefficient & Sig. \\
\hline c & 0.182 & 0.001 \\
a & 0.016 & 0.007 \\
b & 7.623 & 0.000 \\
c & 0.411 & 0.016 \\
\hline
\end{tabular}

Note: the figure in the table is calculated by SPSS22.0. ab $/ \mathrm{c}^{\prime}=30.7 \%$, this indicates the direct effect is significant; there may have other mediating variables between agreeableness and course SWB.

Table 6. Mediating effect test of self-efficacy in conscientiousness and course SWB.

\begin{tabular}{ccc}
\hline coefficient & Regression coefficient & Sig. \\
\hline c & 0.244 & 0.000 \\
a & 0.033 & 0.000 \\
b & 6.439 & 0.000 \\
c' & 0.360 & 0.006
\end{tabular}

Note: the figure in the table is calculated by SPSS 22.0 . ab $/ \mathrm{c}^{\prime}=59.4 \%$, this indicates the direct effect is significant; there may have other mediating variables between conscientiousness and course SWB. 
have mediating effects. Among them, self-efficacy has only a mediating effect between neuroticism and course SWB, and the direct effect is not significant. The proportion of indirect effect between direct effect is $95.2 \%$. The direct effects of extraversion, agreeableness and conscientiousness on courses SWB are significant, which played a part in the intermediary role. The proportion of indirect effects between direct effects are $16.5 \%, 30.7 \%$ and $59.4 \%$, respectively.

\section{Discussion}

Classroom time is the main part of college students' campus life. The experience in the course can not only reflect the subjective feelings of college students' classroom learning but also provide an important reference for the course design. This study proposed the concept of course SWB, aiming to investigate students' psychological perception in the concentrated course cycle, explore the factors affecting course SWB, and provide suggestions for course development. SWB in a course is not only affected by student's innate personality traits, but also by the learning process and living circumstances cumulatively. This study selects the self-efficacy as the mediating variable, examines the mediating effect between college students' personality traits and course SWB, and provides the empirical basis for the design of similar courses.

Through comparative analysis, it is found that students' SWB in the role of CEO is significantly higher than other roles. Students in the role of CEO in the course have higher participation (participating in the course management, leading the competition of enterprises). They got the CEO position after campaign speech, indicating the CEOs have stronger subjective consciousness than others. Female students' SWB is also significantly higher than male students. In the course, female students are generally more serious and have a strong sense of role involvement, which is the most probable reason. The different family sources of students also significantly affect the happiness of students, while the course SWB of rural students is lower than other students. Due to the course's emphasis on teamwork, students with independent personalities have significantly higher course SWB than those with dependent personalities, this result indicates that individuals are more confident in their abilities and have higher positive emotions.

\section{Conclusions}

How do personality traits affect course SWB? This study found that there was no correlation between the openness personality trait and the course SWB. Openness represents an individual's imagination, creativity, curiosity, and sensitivity, indicating that the openness personality trait does not determine the course SWB in a relatively concentrated course cycle and in an environment where imagination is not required. Neurotic personality traits and course SWB show a negative correlation. A person with high neuroticism has stronger stimulation responses to externals, and their emotional regulation ability is not good. They are more likely to experience negative emotions such as anger, anxiety, depres- 
sion. This personality illustrates that individuals with emotional instability in a course are less likely to produce happiness. There is a positive correlation between extroversion and course SWB. Extroversion represents the degree of a person's positive involvement in the outside world. Since the course is a teamwork style, it means that individuals who actively participate in team activities are more likely to feel happiness. Agreeableness represents the attention to cooperation and interpersonal harmony, which is also highly positively correlated with the course SWB. This correlation also indicates that a high teamwork spirit is more likely to experience happiness. Conscientiousness is positively correlated with course SWB, which is a way for us to control, manage and regulate our impulses. This relationship indicates that individuals who avoid trouble and achieve team goals have higher course SWB in a relatively concentrated course cycle. Self-efficacy is an individual's confidence in what they are doing. Self-efficacy also shows a significant positive correlation with course SWB, it illustrates that students with solid knowledge reserves have more confidence in problems they may encounter in course, which is conducive to improving course SWB.

This study also found that self-efficacy plays mediating roles between neuroticism, extraversion, agreeableness, conscientiousness and course SWB respectively except openness. This relationship illustrates the personality traits of students indirectly influence course SWB by the acquired knowledge accumulation. This finding confirms that the mental feeling of students is combined affected by nature and nurture factors. Moreover, self-efficacy has a completely mediating effect between neuroticism and course SWB, indicating that emotional instability can only contribute to course SWB under the combined effect of self-cognition established by acquired experience accumulation. Self-efficacy plays a partial mediating role between extroversion, agreeableness, conscientiousness and course happiness respectively, indicating there are other mediating factors between them, for example, in the study of G.-H. Jiang et al. [10], self-esteem, emotional regulation and achievement motivation all play a mediating role.

This paper discusses the relationship between course SWB and the personality traits, self-efficacy in one course period, puts forward the concept of course SWB and examines by a relatively concentrated and continuous course. Due to the research only chooses one course in one university, further research also needs to expand the scope to verify the results.

\section{Funding}

This study was supported by industry university research collaborative project of Ministry of Education of the PRC (201901266001), virtual simulation experimental teaching project of Anhui province (2019xfxm44). First class project (acylkc201926) and teaching research project (acjyyb2019088) of Anhui university of finance and economics.

\section{Conflicts of Interest}

The authors declare no conflicts of interest regarding the publication of this paper. 


\section{References}

[1] Wu, M. (2000) The Theory Development of Subjective Well-Being in Thirty Years. Advances in Psychological Science, 4, 23-28.

[2] Yao, Y.-L., Kong, Q.-P. and Cai, H.-F. (2016) The Difference Study of Students' Subjective Well-Being in Primary and Middle School. Global Education, 45, 21-29+ 67.

[3] Liu, J.-T. and Zhang, H.-Z. (2013) The Correlation of Middle School Students Subjective Well-Being, Personality Traits, and Self-Harmony. Chinese Mental Health Journal, 27, 680-681.

[4] Niu, Y.-B., Hao, Z.-S., Wang, R.-Z. and Hong, F. (2019) The Relationship between Optimism, Perceived Social Support and Subjective Well-Being of the Elderly: The Mediating Role of Control Strategies. Psychological Development and Education, 35, 227-235.

[5] Yuan, S.-H. and Xing, Z.-J. (2017) On the Relationship Between Left-at-Home Rural Children's Social Welfare and Subjective Well-Being. Chinese Journal of Special Education, 9, 9-14.

[6] Li, Z.-Q., Wang, L. and Zhang, H.-M. (2010) Personality Traits and Subjective Well-Being: The Mediating Role of Emotion Regulation. Psychological Science, 33, 165-167.

[7] Diener, E., Oishi, S. and Lucas, R.E. (2003) Personality, Culture, and Subjective Well-Being: Emotional and Cognitive Evaluations of Life. Annual Review of Psychology, 54, 403-425. https://doi.org/10.1146/annurev.psych.54.101601.145056

[8] Lian, K.-Y., Xie, S.-S. and Lin, R.-M. (2017) The Relationship between Vocational Personality and Subjective Well-Being in Elementary and Secondary School Teachers: The Mediating Role of Work Engagement. Psychological Development and Education, 33, 700-707.

[9] Zhang, R.-P. and Li, Q.-A. (2017) Personality Traits and Subjective Well-Being in Chinese University Students: The Mediated Effect of Confucian Psychological Assets. Psychological Science, 40, 657-663.

[10] Jiang, G.-H. and Meng, Y.-J. (2017) The Relationship Research on Athelte's Personality and Subjective Well-Being. Statistics \& Decision, 3, 112-116.

[11] Bandura, A. (1982) The Assessment and Predictive Generality of Self-Percepts of Efficacy. Journal of Behavior Therapy \& Experimental Psychiatry, 13, 195-199. https://doi.org/10.1016/0005-7916(82)90004-0

[12] Kirkpatrick, M., Delton, A.W. and De, W.H. (2015) Prosocial Effects of MDMA: A Measure of Generosity. Journal of Psychopharmacology, 29, 661-668. https://doi.org/10.1177/0269881115573806

[13] Xi, C., Zhong, M.-T. and Lei, X.-X. (2017) Comparing the Neuroticism Subscale of the NEO-PI-R with That of the NEO-FFI. Chinese Journal of Clinical Psychology, 25, 453-456.

[14] Li, B., Zhang, W.-L. and Zhang, S.-Q. (2016) Research on Influence Factors Model of Learning Satisfaction in the Blended Learning Environment. Journal of Distance Education, 34, 69-75.

[15] Lei, H. and Li, J. (2018) The Relationship between Social Economic Status and Teachers' Caring Behavior: The Mediating Role of Subjective Well-Being. Teacher Education Research, 30, 34-40.

[16] Qiu, L. and Zheng, X. (2005) The Construct of Subjective Well-Being and Its Relationship to the Three Personality Dimensions. Chinese Journal of Applied Psychol- 
ogy, 4, 330-335 + 353 .

[17] Wen, Z.-L. and Ye, B.-J. (2014) Analyses of Mediating Effects: The Development of Methods and Models. Advances in Psychological Science, 22, 731-745.

https://doi.org/10.3724/SP.J.1042.2014.00731 